\title{
Post-Merger Appraisal of Stress Level among Bank Employees: A Case Study
}

\author{
${ }^{*}$ Vijay Joshi¹, K.A. Goyal² \\ 1UCCMS, MLSU, Udaipur, India \\ ${ }^{2}$ BIT-WCAS, Muscat, Oman \\ *vij.joshi18@gmail.com
}

\begin{abstract}
Mergers and Acquisitions (M\&As) is one of the most accepted inorganic strategic tool in the hands of decision makers. Though, it is a major decision as it requires huge investments but it propels the wings of growth instantaneously and such investment decisions are largely based on financial aspects of business. It brings growth as well as unavoidable challenges for Transferor and transferee Company. Such challenges may include work culture related factors and psychological factors, which directly affect the work force of the transformer company as it is observed in case of ICICI Bank and the Bank of Rajasthan Ltd. BoR amalgamation when all the bank employees of BoR agitated. Therefore, the aim of this research paper is to identify the most prominent factors (merger stressors) which affect the stress level of bank employees during post merger. The factors are divided into two heads i.e. work culture related factors and psychological factors which covers total 13 and 11 factors respectively. For this purpose, a large sample of 60 BoR bank employees has been drawn from Udaipur city and the factor analysis has been performed. We found that cultural fit and HR policy framework are two prominent factors for high level of stress and dissatisfaction among bank employees. This study is a small contribution for the betterment of the bank employees and provides guidelines for bank policy makers, strategists, scholars and researchers.
\end{abstract}

Key Words: Merger and Acquisition, Stress Management, Bank, Employees, Factor Analysis

\section{Introduction}

In a dynamic business environment, banks are facing unprecedented turmoil in market as brutal competition, technological up gradation; recession in global economy, stock market volatility and increasing interest rates has increased the dilemma for bankers to deliver better performance. In response to these market challenges, banks around the world are significantly restructuring their assets, operations and contractual relationships with their shareholders, creditors and other financial stakeholders. Corporate restructuring has facilitated many organizations to re-establish their sustainable competitive advantage, respond more swiftly and effectively to new opportunities, threats and unforeseen challenges of the marketplace. Growth opportunities come in a variety of ways and if an industrialist does not respond on time than great amount of energy and resources may be shattered. The remarkable examples for growth strategy is mergers and acquisition (M\&As). M\&As offer grand opportunity for companies to grow and add value to shareholders' wealth. In recent times, we have seen many examples of M\&As in banking industry. Apart from financial issues, there are certain issues which are under considered. When a merger takes place one firm has to dissolve itself into another firm, but it's not just the transfer of assets and liabilities but the lives of respective employees are also associated with it. Kahr (2011) stated that organizational changes affect the performance of the employees during the course of a merger. Cultures of one of the firm determine the level of stress among employees. It is quite obvious that when a merger is announced respective employees of the firm may feel stressed, disoriented, frustrated, confused and even frightened. At a personal level, these feelings can lead to a sense of loss, psychosomatic difficulties, and marital discord as well. At this juncture, it is quite possible that it may augment the level of stress among employees and that is not good on any part. Therefore, this is an attempt to assess the stress level of employees of erstwhile the Bank of Rajasthan Ltd. (BoR) and identify the factors which are responsible for stress.

Conceptual Framework: According to the press release from Reserve Bank of India (RBI) on August 12, 2010, all branches of Bank of Rajasthan Ltd. would function as branches of ICICI Bank Ltd. with effect from August 13, 2010. That was a consequent upon the RBI sanctioning the Scheme of Amalgamation of Bank of Rajasthan Ltd. with ICICI Bank Ltd. the Scheme has been sanctioned in exercise of the powers contained in sub-section (4) of section 44A of the Banking Regulation Act, 1949. 
Stress: We need to understand the term 'stress' which was coined by Hans Selye in 1936. He defined it as "the non-specific response of the body to any demand for change". Stress management can be defined as interventions designed to reduce the impact of stressors in the workplace. These can have an individual focus, aimed at increasing an individual's ability to cope with stressors. The goal of Stress Management is to manage the stress of everyday life among employees. Many different methods may be employed, such as biofeedback, meditation and massage. Counselors work with individuals in order to determine what stress management program will work best for that person.

Mergers and Acquisitions: It is evident from recent past that Mergers and Acquisitions are well-known strategic tools for banks in India. It is an end of the continuum of alternatives companies have in combining with each other. The least intense and complex from of combination is licensing. Next come alliances, partnerships and subsequently joint ventures. The amount of penetration in market risk, profits, and control depends on the type of combination strategy. It is the mergers and acquisitions that requires huge amount of investment, consequently, greater amount of market penetration, good amount of profits, risks and control over assets ban be obtained. Bose (2007) opined that the banking sector here in India has been active in Mergers and Acquisitions ever since Section 45 was incorporated in the Banking Act in 1960. This section empowered the RBI to initiate the process of amalgamation of weak banks with strong ones at times when the net realizable assets of a bank fell below 90 percent of its deposits, but with the approval of the government. This was aimed at averting bank failures which were as rampant here as they were in other countries in those days.

\section{Objectives of the Study}

- To assess the stress level of bank employees' (post merger).

- To assess the satisfaction level of bank employees after merger.

- To identify the stressors in context with mergers and acquisitions

\section{Literature Review}

Schweiger and Ivancevich (1985) studied the human factor in merger and acquisition and identified some common merger stressors which include uncertainty, insecurity, and fears concerning job loss, job changes, compensation changes, and changes in power, status, and prestige. These stressors should be given utmost care in pre-merger strategic issues. Ivancevich, Schweiger and Power (1987) studied the merger stress process, stages of the merger process and the sources of stress created and choosing guidelines and interventions to encourage more effective management of merger stress. They suggested some measures to effectively manage merger stress, like prevention, to reduce the actual stress-inducing merger events; secondly, reappraisal of employee which refers to changing initial cognitive appraisal of a situation and at last effective stress management and professional help which supports those employees that are already stressed. Schweiger and Weber (1989) suggested that Mergers and acquisitions (M\&As) are corporate events that have the potential to create severe personal trauma and stress which can result in psychological, behavioral, health, performance, and survival problems for both the individuals and companies involved. With the increasing size and number of M\&As transacted and the number of employees affected, it is essential that executives and human resource professionals pay greater attention to understanding the sequence of actions and reactions associated with the process. Schweiger and Denisi (1991) conducted a longitudinal field experiment to evaluate the various effects of a communication program on employees of an organization; they called it a realistic merger preview. This study was intended to measure the effects of mergers and acquisitions on employees. Their results suggested that realistic communication during a merger process in the form of a realistic merger preview can help the employees to get through the process of merger. As illustrated by the significantly lower measures on global stress and perceived uncertainty and significantly higher on job satisfaction, commitment and selfreported performance for the experimental group, exposed to the communication program.

Rajeshwari (1992) identified the potent stress situations (stimulus) of bank employees and then classified them into factors relating to organizational policy, structure, process, physical working conditions, group behavior and others. Researcher concluded that structural rigidity, poor physical working conditions and extra organizational factors to be potent stressors. Cartwright and Cooper (1993) studied the human aspects of merger and acquisition and the impact of such a major change event has on employee health and well being which has received relatively little research attention. They took the sample size of 157 middle managers involved in the merger of two U.K. Building Societies. They found that Post-merger measures of mental health to be a stressful life event, even when there is a high degree 
of cultural compatibility between the partnering organizations. Weber (1996) assessed the role of corporate cultural fit, autonomy removal, and commitment of managers to the merger in predicting effective integration between merger partners in different industry sectors. He found that relationship was very complex; they varied across industries and had different relationships with different measures of performance. Further, he found that cultural differences at the top management level were most likely to influence the merging organizations' ability to realize synergies. According to Weber, Shenkar \& Raveh (1996) cultural fit has been acknowledged to be a potentially important factor in mergers and acquisitions. Researchers examined both international and domestic mergers assessed the relative role of national and corporate cultural fit in predicting effective integration between merger partners. The innovative, nonparametric co-plot method was introduced, and its main advantage-the simultaneous consideration of both variables and observations was utilized to explore cultural fit in the two groups of mergers. The findings confirmed that national and corporate cultures were separate constructs with variable attitudinal and behavioral correlates. Panchal and Cartwright (2001) investigated post-merger stress in a sample of field sales employees. A survey methodology was used to examine group differences, comparing those from the two pre-merger companies and those newly merged organization. Results revealed that group differences in both sources and effects of stress existed. Those from the dominant pre-merger company reported the highest stress levels and most negative work attitudes.

Buono and Bowditch (2003) used longitudinal and cross-sectional field study, interviews, organizational surveys, archival research and bibliographical search of mergers and acquisition literature for eight years. Their study is based on human side of such organizational combinations in terms of the personal issues involved in mergers at both the psychological and cultural levels. They found a relationship between employee attitude and a number of work related behavior such as turnover, absenteeism, tardiness, strikes and grievances, and quality of job performance. It was concluded that a merger or acquisition is ultimately a human process. Focused efforts on and sensitivity to what people are experiencing are necessary if managers hope to decrease the costs involved for both individual employees and the organization (p. 133). Zollo \& Singh, (2004) introduced a knowledge-based view of corporate acquisitions and tests the post-acquisition consequences on performance of integration decisions and capabilitybuilding mechanisms. The study shows how the acquiring firm decides both how much to integrate the acquired firm and the extent to which it replaces this firm's top management team. They also studied how to manage the post-acquisition integration process by tacitly accumulating acquisition experience and explicitly codifying it in manuals, systems, and other acquisition-specific tools. Researchers used a sample of 228 acquisitions in the U.S. banking industry and found that knowledge codification strongly and positively influences acquisition performance, while experience accumulation does not. Moreover, increasing levels of post-acquisition integration strengthen the positive effect of codification. Finally, the level of integration between the two merged firms significantly enhances performance, while replacing top managers in the acquired firm negatively impacts performance, all else being equal. Ranft (2006) developed and studied a model of knowledge-based resource transfer during acquisition integration on a sample of 75 high-tech acquisitions. Results indicated that transferring tacit knowledge is both desirable and difficult in acquisitions of technology intensive firms. It was found that acquired firm autonomy preserves tacit knowledge, while rich communication and retention of key employees facilitates transferring knowledge in acquisitions.

Lodorfos and Boateng (2006) examined the role played by culture and provided a framework for enhancing the success of mergers and acquisitions. Their study was based on 32 interviews with senior managers of 16 merger and acquisition deals in the chemical industry. They found that cultural differences between the merging firms were key elements determining the effectiveness of the integration process and consequently the success of M\&As. Furthermore, the study also found that, although managers agree that cultural differences create organizational challenges, yet the attention given to cultural integration issues during M\&As are unconvincing and in some cases reactive. Their study suggested a four staged approach in dealing with cultural differences. The managerial implication of this finding is that cultural fit constitutes a key factor in M\&As' success and should be given the necessary attention at all stages of M\&As, good pre-merger planning with culture placed at the heart of integration strategies and implementation and the creation of a positive atmosphere for the change. Sakas and Triantafyllopoulos (2009) examined the factors staff's beliefs, attitudes and social representations vis-àvis the part it plays during the negotiation process in the effort of the two leaders of the Greek banking branch to merge. They used codification by means of software, so as to clarify the trends for negotiations in win-win conditions. They concluded that the private or public character of each banking organization involved in the negotiation process of aiming at a merger will affect its strategic choices in relation to the 
role played by human beliefs and professional attitudes during the negotiations. Additionally, the research pointed out some elements that were explained and justified by the existing circumstances in the particular banking area. The fear of change, the stress, the insecurity and the loss of morale are also pointed out as being significant factors. Marmenout (2010) conducted experimental study to examine how employees make sense of a merger announcement and investigates the relationship between deal characteristics (culture clash potential, degree of integration, position in deal structure) and employee attitudes. As employees make sense of the merger, higher perceived uncertainty is associated with greater dysfunctional outcomes.

Khattak et al (2011) examined the occupational stress in the banking sector of Pakistan. A total of 237 bank employees from different commercial banks participated in the survey. They used self-reported questionnaire. Descriptive, correlation and regression statistical tools were used to analyze data. The results revealed the potential stressors like workload, working hours, technological problem at work, inadequate salary, time for family and job worries at home were the significant sources of stress in the banking sector. The study suggested that the elements which are creating stress leading to burnout. Moreover, the significant symptoms of burnout as revealed by the results were back pain, extreme tiredness, headache and sleep disturbance. All stressors (Organization, Job, Relationship at work, work environment and family work interface) were significantly correlated to all burnouts (Physical, Psychological and Organizational). All the stress elements significantly predicted burnout in the banking sector of Pakistan. The changing work pattern is creating stress for the bank employees and these stressors are leading to burnout. Clarke and Salleh (2011) conducted a qualitative study examining the emotional impact of a merger between two banking institutions on managers in Brunei. The distinctive national culture representing a fusion of Malay and Islamic values was found to influence the emotional impact of this merger. These values place less emphasis on personal control as a means for dealing with uncertainty. The findings suggest that Western transactional models of perceived control to explain how people manage change may have far more limited application within a Bruneian context.

Shook and Roth (2011) conducted a qualitative study using a constant comparative method to assess the perspectives of HR practitioners based on their experiences with mergers, acquisitions, and downsizings. They interviewed 13 HR practitioners to collect the data. They found that HR practitioners were not involved in planning decisions related to downsizings, mergers, and/or acquisition. Neither the practitioners in this study nor other members of the HR team in their organizations had an upfront due diligence role in these change initiatives. Goyal and Joshi (2011) opined that M\&As offer great opportunities for companies to grow and add value to shareholders' wealth. Moreover, they have concluded that M\&As are expected to increase in branches, market share, geographical reach or penetration in market, value and efficiency of the company and thereby increase shareholders' value as we have observed in the case of ICICI Bank and the Bank of Rajasthan Ltd. merger. But, they have observed that in this case agitation by employees was a major concern. These incidences create stress among bank employees. Joshi and Goyal (2012) studied various stressors which contribute in increasing the level of stress among employees. These included uncertainty, insecurity, fears concerning job loss, job changes, compensation, changes in power, status, prestige, workload, working hours, technological problem at work, inadequate salary, time for family job worries at home group differences and communication.

\section{Methodology}

This is a strategic move by ICICI Bank in Rajasthan, which has significantly improved the geographic network and market share in Rajasthan. But when the announcement about this merger was made, the employees' of erstwhile the Bank of Rajasthan ltd got agitated. Here the problem arises that what is the perception of bank employees about this merger? Are they satisfied or not? Therefore this attempt is made to study the stress level of employees and their post merger satisfaction level.

Sampling Distribution: Total 463 branches of BOR were operating across India before merger and out of this total 293 Branches were operating in Rajasthan. Out of these 293 branches, there were total 72 branches in Udaipur division and out of these total 31 branches were operating in Udaipur district. For our study purpose, we consider only 14 branches of Udaipur city to determine our sampling frame. We employed Proportional Stratified Sampling method for sampling purpose. 
Sample Size: For purpose of our study a sample of 60 bank employees out of 110 (appx.) employees from managerial and executive levels of erstwhile BoR is drawn.

Data Type: Both primary and secondary data will be used.

Research Instrument: Schedules (structured) and personal interviews are used for primary data collection. We introduced 26 variables (found from available literature) to frame questions and five point Likert scale is used for measuring attitude and level of stress of employees. To find the stress and satisfaction level of employees, they were asked to rank their stress and satisfaction level on the scale of $1-5$, where 1 means highly dissatisfied \& 5 means highly satisfied. The internal consistency has been checked with the help of Cronbach's Alpha and value obtained by using SPSS (student version 15.0) is .983 which is usually considered as excellent.

Research Tools: Paired sample t-test, weighted arithmetic mean and factor analysis is used with the help of SPSS (student version 13) to test the hypothesis, identification of factors and analyze the data.

Formula of Student's paired sample t-test employed in the study.

$$
t=\frac{\bar{d}}{s / \sqrt{n-1}}
$$

Where;

$\mathrm{d}=\mathrm{x}-\mathrm{y}$

$\bar{d}=\frac{\sum d}{n}$

$s=\sqrt{\frac{\sum(d-\bar{d})^{2}}{n}}$

\section{Hypotheses Formulated}

$\mathrm{H}_{01}$ : There is no significant difference between the pre-merger and post-merger level of stress among bank employees.

$\mathrm{H}_{02}$ : There is no significant difference between the pre-merger and post-merger satisfaction level among employees.

\section{Data Analysis}

Table 1: Demographic details of Respondents

\begin{tabular}{llll}
\hline Demographics & & Frequency & Percent \\
\hline \multirow{3}{*}{ Gender } & Male & 42 & 70.0 \\
& Female & 18 & 30.0 \\
& Total & 60 & 100.0 \\
\multirow{5}{*}{ Age } & $31-40$ & 14 & \\
& $41-50$ & 27 & 23.3 \\
& $51-60$ & 19 & 45.0 \\
& Total & 60 & 31.7 \\
& & & 100.0 \\
Designation & Chief Manager & 10 & \\
& Senior Manager & 13 & 3.3 \\
& Deputy Manager & 20 & 16.7 \\
& Assistant Manager & 15 & 21.7 \\
& Clerk & 60 & 33.3 \\
& Total & & 25.0 \\
\hline
\end{tabular}

Source: Primary Data 
Table 2: Cross Tabulation

\begin{tabular}{|c|c|c|c|c|}
\hline \multicolumn{5}{|c|}{ Age * Gender Cross Tabulation } \\
\hline & & $\begin{array}{l}\text { Gender } \\
\text { Male }\end{array}$ & Female & Total \\
\hline & $31-40$ & 12 & 2 & 14 \\
\hline \multirow[t]{2}{*}{ Age } & $41-50$ & 18 & 9 & 27 \\
\hline & $51-60$ & 12 & 7 & 19 \\
\hline Total & & 42 & 18 & 60 \\
\hline \multicolumn{5}{|c|}{ Designation * Gender Cross Tabulation } \\
\hline & Chief Manager & 2 & 0 & 2 \\
\hline \multirow{4}{*}{ Designation } & Senior Manager & 7 & 3 & 10 \\
\hline & Deputy Manager & 9 & 4 & 13 \\
\hline & Assistant Manager & 15 & 5 & 20 \\
\hline & Clerk & 9 & 6 & 15 \\
\hline Total & & 42 & 18 & 60 \\
\hline
\end{tabular}

Source: Primary Data

Analysis of Merger Stressors: As we can see in below mentioned table 3 that uncertainty is the major factor which creates stress among employees after merger and it is ranked first by respondents. The next merger stressor is Insecurity which is followed by technology used and we can say on the basis of outcome in personal interview that employees felt insecure after merger and they also faced problem initially on technology front. The factor which is ranked as fourth and fifth is job changes and job loss respectively. It clearly shows the fear in the minds of bank employees. The sixth and seventh factors are reporting system and working hours respectively. In the new work environment it might be possible that employees may feel uncomfortable but they gradually become habitual to these practices. It is evident that the working hours are long at ICICI Bank Ltd. as compared to the erstwhile BoR. The relationship with peers and boss are ranked as eighth and ninth positions which are followed by supervision and human resource practices at tenth and eleventh place respectively. The further ranks are occupied by Grievance Handling, Changes in power, Responsibility, Departmentation, and Performance Appraisal and so on as mentioned in the table.

Table 3: Rank Analysis of Factors Selected for Study

\begin{tabular}{|c|c|c|c|c|c|c|c|c|c|c|}
\hline \multicolumn{2}{|c|}{ Weights } & \multirow{2}{*}{$\begin{array}{l}1 \\
\text { Strongly } \\
\text { Disagree }\end{array}$} & \multirow{2}{*}{$\begin{array}{l}2 \\
\text { Disagree }\end{array}$} & \multirow{2}{*}{$\begin{array}{l}3 \\
\text { Neutral }\end{array}$} & \multirow{2}{*}{$\begin{array}{l}4 \\
\text { Agree }\end{array}$} & \multirow{2}{*}{$\begin{array}{l}5 \\
\text { Strongly } \\
\text { agree }\end{array}$} & \multirow{2}{*}{ Total } & \multirow{2}{*}{$\begin{array}{l}\text { Weighted } \\
\text { Total }\end{array}$} & \multirow{2}{*}{$\begin{array}{l}\text { Weighted } \\
\text { Mean }\end{array}$} & \multirow{2}{*}{ Rank } \\
\hline $\begin{array}{l}\text { S. } \\
\text { No. }\end{array}$ & Factors Selected & & & & & & & & & \\
\hline 1 & Uncertainty & 0 & 1 & 11 & 15 & 33 & 60 & 260 & 17.33 & 1 \\
\hline 2 & Insecurity & 2 & 1 & 8 & 18 & 31 & 60 & 255 & 17.00 & 2 \\
\hline 3 & Job loss & 6 & 5 & 8 & 11 & 30 & 60 & 234 & 15.60 & 5 \\
\hline 4 & Job changes & 1 & 14 & 1 & 11 & 33 & 60 & 241 & 16.07 & 4 \\
\hline 5 & $\begin{array}{l}\text { Compensation } \\
\text { changes }\end{array}$ & 36 & 12 & 10 & 2 & 0 & 60 & 98 & 6.53 & 25 \\
\hline 6 & Changes in power & 10 & 8 & 4 & 36 & 2 & 60 & 192 & 12.80 & 13 \\
\hline 7 & Status & 17 & 21 & 10 & 12 & 0 & 60 & 137 & 9.13 & 17 \\
\hline 8 & Prestige & 23 & 22 & 12 & 2 & 1 & 60 & 116 & 7.73 & 23 \\
\hline 9 & Growth & 15 & 26 & 18 & 1 & 0 & 60 & 125 & 8.33 & 22 \\
\hline 10 & Responsibility & 3 & 8 & 26 & 23 & 0 & 60 & 189 & 12.60 & 14 \\
\hline 11 & Work itself & 19 & 14 & 24 & 1 & 2 & 60 & 133 & 8.87 & 19 \\
\hline 12 & Working Hours & 8 & 6 & 8 & 10 & 28 & 60 & 224 & 14.93 & 7 \\
\hline 13 & Technology used & 1 & 5 & 10 & 12 & 32 & 60 & 249 & 16.60 & 3 \\
\hline 14 & $\begin{array}{l}\text { Grievance } \\
\text { Handling }\end{array}$ & 0 & 17 & 18 & 17 & 8 & 60 & 196 & 13.07 & 12 \\
\hline 15 & Designation & 26 & 10 & 12 & 8 & 4 & 60 & 134 & 8.93 & 18 \\
\hline 16 & change of branch & 36 & 5 & 14 & 5 & 0 & 60 & 108 & 7.20 & 24 \\
\hline 17 & HR Practices & 8 & 0 & 12 & 30 & 10 & 60 & 214 & 14.27 & 11 \\
\hline
\end{tabular}




\begin{tabular}{|c|c|c|c|c|c|c|c|c|c|c|}
\hline 18 & Compensation & 40 & 10 & 6 & 2 & 2 & 60 & 96 & 6.40 & 26 \\
\hline 19 & $\begin{array}{l}\text { Performance } \\
\text { Appraisal }\end{array}$ & 23 & 0 & 21 & 10 & 6 & 60 & 156 & 10.40 & 16 \\
\hline 20 & Reporting System & 8 & 3 & 8 & 18 & 23 & 60 & 225 & 15.00 & 6 \\
\hline 21 & Centralization & 8 & 34 & 15 & 3 & 0 & 60 & 133 & 8.87 & 20 \\
\hline 22 & Departmentation & 1 & 24 & 16 & 12 & 7 & 60 & 180 & 12.00 & 15 \\
\hline 23 & Company Policy & 10 & 43 & 0 & 2 & 5 & 60 & 129 & 8.60 & 21 \\
\hline 24 & Supervision & 0 & 0 & 32 & 19 & 9 & 60 & 217 & 14.47 & 10 \\
\hline 25 & $\begin{array}{l}\text { Relationship with } \\
\text { boss }\end{array}$ & 6 & 12 & 2 & 18 & 22 & 60 & 218 & 14.53 & 9 \\
\hline 26 & $\begin{array}{l}\text { Relationship with } \\
\text { peers }\end{array}$ & 5 & 11 & 6 & 14 & 24 & 60 & 221 & 14.73 & 8 \\
\hline
\end{tabular}

Source: Primary Data Collected through Schedules

Table 4: Descriptive Statistics

\begin{tabular}{|c|c|c|c|c|c|c|}
\hline Particulars & & Frequency & Percent & Mean & $\begin{array}{l}\text { Standard } \\
\text { Deviation }\end{array}$ & Variance \\
\hline \multirow{4}{*}{ Stress Level Pre-Merger } & Low & 43 & 71.7 & \multirow{4}{*}{1.33} & \multirow{4}{*}{0.572} & \multirow{4}{*}{0.328} \\
\hline & Moderate & 14 & 23.3 & & & \\
\hline & High & 3 & 5.0 & & & \\
\hline & Total & 60 & 100.0 & & & \\
\hline \multirow{4}{*}{ Stress Level Post-Merger } & Low & 5 & 8.3 & \multirow{4}{*}{2.68} & \multirow{4}{*}{0.624} & \multirow{4}{*}{0.390} \\
\hline & Moderate & 9 & 15.0 & & & \\
\hline & High & 46 & 76.7 & & & \\
\hline & Total & 60 & 100.0 & & & \\
\hline Coticfoction & Agree & 28 & 46.7 & \multirow{3}{*}{4.53} & \multirow{3}{*}{0.503} & \multirow{3}{*}{0.253} \\
\hline \multirow{2}{*}{$\begin{array}{l}\text { Satisfaction } \\
\text { Merger }\end{array}$} & Strongly Agree & 32 & 53.3 & & & \\
\hline & Total & 60 & 100.0 & & & \\
\hline Level Post- & $\begin{array}{l}\text { Strongly } \\
\text { Disagree }\end{array}$ & 13 & 21.7 & \multirow{4}{*}{2.15} & \multirow{4}{*}{0.755} & \multirow{4}{*}{0.570} \\
\hline \multirow{2}{*}{$\begin{array}{l}\text { Satisfaction } \\
\text { Merger }\end{array}$} & Disagree & 25 & 41.7 & & & \\
\hline & Neutral & 22 & 36.7 & & & \\
\hline & Total & 60 & 100.0 & & & \\
\hline
\end{tabular}

Source: Primary Data

Analysis of above mentioned table (no. 4) shows that majority of employees (71.7\%) were having low level of stress before merger, while the situation is reversed after merger. In ICICI $76.7 \%$ of employees were feeling high level of stress. To measure the stress level of employees, they were asked to rate their opinion on various variables and If we compare the mean scores of their stress level we find that pre merger stress level was low (1.33) and on the other hand post merger stress level was high (2.68). As we can see in above table no. 4 that 53.3\% BoR employees were strongly agree when they were asked about their satisfaction level and majority i.e. $41.7 \%$ of erstwhile BoR employees showed disagreement to the same statement. The comparison of mean scores in table no. of satisfaction level shows that employees of BoR were highly satisfied (4.53) while after becoming the employees of ICICI they are Dissatisfied (2.15).

Table 5: Hypothesis Testing

\begin{tabular}{|c|c|c|c|c|c|c|}
\hline \multicolumn{7}{|c|}{ Paired Samples Test } \\
\hline & & Mean & Std. Deviation & $\begin{array}{l}\text { Std. Error } \\
\text { Mean }\end{array}$ & t statistic & H0: Accept/Reject \\
\hline $\mathrm{H}_{0} 1$ & $\begin{array}{l}\text { Stress Level Pre-Merger and } \\
\text { Post-Merger }\end{array}$ & -1.350 & 0.709 & 0.092 & -14.751 & Rejected \\
\hline $\mathrm{H}_{0} 2$ & $\begin{array}{l}\text { Satisfaction Level Pre-Merger } \\
\text { and Post-Merger }\end{array}$ & 2.383 & 0.922 & 0.119 & 20.017 & Rejected \\
\hline
\end{tabular}

Source: Primary Data Calculated through SPSS (Student Version 15.0) 
Since, calculated value i.e. -14.751 is greater than tabulated value at $5 \%$ level of significance and 59 degrees of freedom i.e. 2.000 (appx.), so our hypothesis rejected and hence we can conclude that there is high significant difference between pre-merger and post-merger stress level of erstwhile BoR employees. Since, calculated value i.e. 20.017 is greater than tabulated value at $5 \%$ level of significance and 59 degrees of freedom i.e. 2.000 (appx.), so our hypothesis rejected and hence we can conclude that there is high significant difference between pre-merger and post-merger satisfaction level of erstwhile BoR employees. After testing the above hypotheses, we can see that there is significant difference in stress level and satisfaction level of employees. Here, the question arises what are the factors which are contributing in determination of above results. Therefore, we conduct factor analysis to identify the relevant factors which are responsible for stress and dissatisfaction among bank employees and which can be taken care in future course of merger and acquisition in advance.

Factor Analysis: To test the adequacy of sampling, Kaiser-Meyer-Oklin measure of sampling adequacy is computed which is found to be .909. It indicates that sample is good enough for sampling. Moreover the overall significance of correlation matrices has been tested with Bartlett Test (approx. Chi-square = 3523.618 and significant at 0.000 ) at 325 degree of freedom which provide well support for the validity of data for factor analysis.

Table 6: Results of Kaiser-Meyer-0lkin

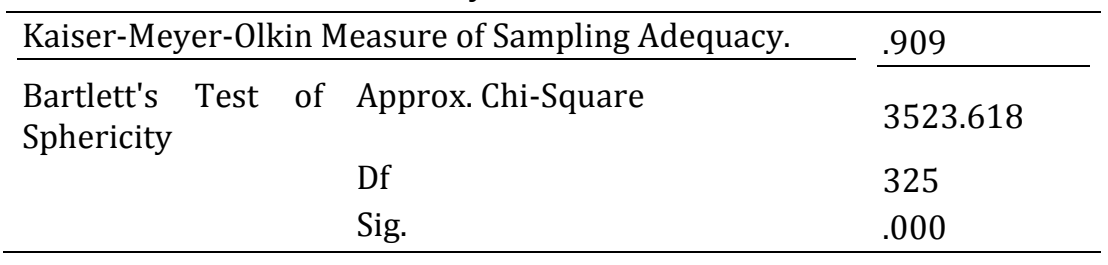

Source: Primary Data Calculated through SPSS (Student Version 15.0)

Now, we can proceed with factor analysis and the result of 26 factors in table no. 6 shows that there are two key factors having Eigen values more than 1 and as per extraction sum of squared loadings, percentage variance explained by the these factors is 80.292 and 10.269 respectively. The cumulative percent is 90.561 which reveal that these two factors are prominent enough in causing dissatisfaction and high level of stress.

Table 7: Total Variance Explained

\begin{tabular}{|c|c|c|c|c|c|c|c|c|c|}
\hline \multirow[b]{2}{*}{ Component } & \multicolumn{2}{|c|}{ Initial Eigenvalues } & \multirow[b]{2}{*}{$\begin{array}{l}\text { Cumulative } \\
\%\end{array}$} & \multicolumn{2}{|c|}{$\begin{array}{l}\text { Extraction } \\
\text { Loadings }\end{array}$} & f Squared & $\begin{array}{l}\text { Rotation } \\
\text { Loadings }\end{array}$ & Sums of & Squared \\
\hline & Total & $\begin{array}{l}\% \text { of } \\
\text { Variance }\end{array}$ & & Total & $\begin{array}{l}\% \text { of } \\
\text { Variance }\end{array}$ & $\begin{array}{l}\text { Cumulative } \\
\%\end{array}$ & Total & $\begin{array}{l}\% \text { of } \\
\text { Variance }\end{array}$ & $\begin{array}{l}\text { Cumulative } \\
\%\end{array}$ \\
\hline 1 & 20.876 & 80.292 & 80.292 & 20.876 & 80.292 & 80.292 & 12.636 & 48.600 & 48.600 \\
\hline 2 & 2.670 & 10.269 & 90.561 & 2.670 & 10.269 & 90.561 & 10.910 & 41.961 & 90.561 \\
\hline 3 & .566 & 2.175 & 92.737 & & & & & & \\
\hline 4 & .399 & 1.535 & 94.272 & & & & & & \\
\hline 5 & .296 & 1.140 & 95.411 & & & & & & \\
\hline 6 & .202 & .777 & 96.188 & & & & & & \\
\hline 7 & .181 & .695 & 96.883 & & & & & & \\
\hline 8 & .157 & .603 & 97.486 & & & & & & \\
\hline 9 & .119 & .458 & 97.943 & & & & & & \\
\hline 10 & .098 & .376 & 98.320 & & & & & & \\
\hline 11 & .065 & .249 & 98.569 & & & & & & \\
\hline 12 & .062 & .237 & 98.806 & & & & & & \\
\hline 13 & .055 & .210 & 99.016 & & & & & & \\
\hline 14 & .047 & .182 & 99.198 & & & & & & \\
\hline 15 & .034 & .131 & 99.329 & & & & & & \\
\hline 16 & .029 & .112 & 99.441 & & & & & & \\
\hline 17 & .027 & .106 & 99.547 & & & & & & \\
\hline 18 & .024 & .093 & 99.639 & & & & & & \\
\hline
\end{tabular}




$\begin{array}{llll}19 & .022 & .085 & 99.724 \\ 20 & .020 & .076 & 99.800 \\ 21 & .016 & .061 & 99.861 \\ 22 & .012 & .046 & 99.907 \\ 23 & .010 & .039 & 99.947 \\ 24 & .006 & .025 & 99.971 \\ 25 & .004 & .017 & 99.988 \\ 26 & .003 & .012 & 100.000\end{array}$

Extraction Method: Principal Component Analysis

Source: Primary Data Calculated through SPSS (Student Version 15.0)

Table 8: Rotated Component Matrix (a)

\begin{tabular}{|c|c|c|c|}
\hline \multirow{2}{*}{ S. No. } & \multirow{2}{*}{ Factors } & \multicolumn{2}{|c|}{ Component } \\
\hline & & 1 & 2 \\
\hline 1 & Working Hour & 0.900 & 0.397 \\
\hline 2 & Technology used & 0.939 & 0.262 \\
\hline 3 & Grievance Handling & 0.620 & 0.732 \\
\hline 4 & Designation Given & 0.452 & 0.858 \\
\hline 5 & Change of branch & 0.262 & 0.939 \\
\hline 6 & HR Practices & 0.817 & 0.435 \\
\hline 7 & Compensation & 0.158 & 0.957 \\
\hline 8 & Performance Appraisal & 0.617 & 0.714 \\
\hline 9 & Reporting System & 0.883 & 0.416 \\
\hline 10 & Centralization & 0.521 & 0.748 \\
\hline 11 & Departmentation & 0.515 & 0.815 \\
\hline 12 & Company Policy & 0.300 & 0.760 \\
\hline 13 & Supervision & 0.405 & 0.840 \\
\hline 14 & Relationship with boss & 0.854 & 0.464 \\
\hline 15 & Relationship with peers & 0.860 & 0.465 \\
\hline 16 & Uncertainty & 0.894 & 0.348 \\
\hline 17 & Insecurity & 0.879 & 0.316 \\
\hline 18 & Job loss & 0.924 & 0.342 \\
\hline 19 & Job changes & 0.908 & 0.323 \\
\hline 20 & Compensation changes & 0.292 & 0.920 \\
\hline 21 & Changes in power & 0.896 & 0.348 \\
\hline 22 & Status & 0.579 & 0.767 \\
\hline 23 & Prestige & 0.490 & 0.806 \\
\hline 24 & Growth & 0.660 & 0.668 \\
\hline 25 & Responsibility & 0.784 & 0.495 \\
\hline 26 & Work itself & 0.638 & 0.680 \\
\hline
\end{tabular}

Extraction Method: Principal Component Analysis.

Rotation Method: Varimax with Kaiser Normalization.

a Rotation converged in 3 iterations.

Source: Primary Data Calculated through SPSS (Student Version 15.0) 
The above table 8 shows that each statement corresponding to the highlighted factor loading which is correlated with the factors corresponding to that factor loading. Higher the factor loading, stronger is the correlation between the factors and statement. On the basis of rotated component matrix the factor extraction table has been prepared which is as under.

Table No. 9

Table 9: Factor Extraction Table

\begin{tabular}{|c|c|c|c|}
\hline S. No. & Factors & \% of Variance & \multirow{2}{*}{ Loading } \\
\hline \multicolumn{2}{|c|}{ Factor 1 (Cultural Fit) } & 48.600 & \\
\hline 1 & Working Hour & & 0.900 \\
\hline 2 & Technology used & & 0.939 \\
\hline 3 & HR Practices & & 0.817 \\
\hline 4 & Reporting System & & 0.883 \\
\hline 5 & Relationship with boss & & 0.854 \\
\hline 6 & Relationship with peers & & 0.860 \\
\hline 7 & Uncertainty & & 0.894 \\
\hline 8 & Insecurity & & 0.879 \\
\hline 9 & Job loss & & 0.924 \\
\hline 10 & Job changes & & 0.908 \\
\hline 11 & Changes in power & & 0.896 \\
\hline 12 & Growth & & 0.660 \\
\hline 13 & Responsibility & & 0.784 \\
\hline \multicolumn{2}{|c|}{ Factor 2 (HR Policy Framework) } & 41.961 & \\
\hline 14 & Grievance Handling & & 0.732 \\
\hline 15 & Designation Given & & 0.858 \\
\hline 16 & Change of branch & & 0.939 \\
\hline 17 & Compensation & & 0.957 \\
\hline 18 & Performance Appraisal & & 0.714 \\
\hline 19 & Centralization & & 0.748 \\
\hline 20 & Departmentation & & 0.815 \\
\hline 21 & Company Policy & & 0.760 \\
\hline 22 & Supervision & & 0.840 \\
\hline 23 & Compensation changes & & 0.920 \\
\hline 24 & Status & & 0.767 \\
\hline 25 & Prestige & & 0.806 \\
\hline 26 & Work itself & & 0.680 \\
\hline
\end{tabular}

Source: Table No. 8

Interpretation: As we can see in above table no. 9 that the prominent factor which is outcome of this factor analysis is named as Cultural Fit and variables contributing to the factor are Working Hour (0.900), Technology used (0.939), HR Practices (0.817), Reporting System (0.883), Relationship with boss (0.854), Relationship with peers (0.860), Uncertainty (0.894), Insecurity (0.879), Job loss (0.924), Job changes (0.908), Changes in power (0.896), Growth (0.660), Responsibility (0.784) respectively. The second factor which is identified is HR Policy Framework and the variables contribute to the factors includes Grievance Handling (0.732), Designation Given (0.858), Change of branch (0.939), Compensation (0.957), Performance Appraisal (0.714), Centralization (0.748), Departmentation (0.815), Company Policy $(0.760)$, Supervision $(0.840)$, Compensation changes $(0.920)$, Status $(0.767)$, Prestige $(0.806)$, and Work itself $(0.680)$ respectively. 


\section{Conclusion}

As per the above discussion we can draw the conclusion that mergers and acquisition is an ongoing activity in the world of business but apart from financial aspects human resource aspects are also considered before taking such decisions. It is quite clear that sick banks must be merged in large banks to protect the rights of consumers. Here, transferor and transferee banks create synergy, customers also get benefits of the merger but in some instances employees do not get satisfaction in the transferee company. In this study we found that mergers and acquisition is the activity which created stress among bank employees of erstwhile Bank of Rajasthan Ltd. When the BoR was about to be merged in the ICICI bank all the employees were against this merger. As we found that post merger satisfaction level is very low and the stress is very high. The study also reveals the two most prominent factors are Cultural Fit and HR Policy Framework during the course of a merger. Thus, we can say that the changes which occur during the course of mergers and acquisitions, if not managed at the right time than the level of stress can increase.

\section{References}

Bose, J. (2007). Bank mergers in India the saga of status quo. In J. Bose (Ed.), Bank mergers: The Indian scenario ( $1^{\text {st }}$ ed. pp. 3-23). Hyderabad: The ICFAI University Press.

Buono, A. F. \& Bowditch, J. L. (2003). Human side of mergers and acquisitions: Managing collisions between people, cultures, and organizations. Washington, D. C., USA: Beard Books.

Cartwright, S. \& Cooper, C. L. (1993). The Psychological Impact of Merger and Acquisition on the Individual: A Study of Building Society Managers. Human Relations, 46(3), 327-347.

Clarke, N. \& Salleh, N. M. (2011). Emotions and their management during a merger in Brunei. Human Resource Development International, 14(3), 291-304.

Goyal, K. A. \& Joshi, V. (2011). Mergers in Banking Industry of India: Some Emerging Issues. Asian Journal of Business and Management Sciences, 1(2), 157-165.

Ivancevich, J. M., Schweiger, D. M. \& Power F. R. (1987). Strategies for managing human resources during mergers and acquisitions. Human Resource Planning, 10(1), 19-35.

Joshi, V. \& Goyal, K. A. (2012). Stress Management among Bank Employees: With Reference to Mergers and Acquisitions. International Journal of Business and Commerce, 1(5), 22-31.

Kahr, A. (2011). Profitability comes down to staff cuts. American Banker, 176(127), 8. Downloaded on December 09, 2011, from Corporate Resource Net, Pacific Institute of Management.

Khattak, J. K., Khan, M. A., Haq, A. U., Arif, M. \& Minhas, A. A. (2011). Occupational stress and burnout in Pakistan's banking sector. African Journal of Business Management, 5(3), 810-817.

Lodorfos, G. \& Boateng, A. (2006). The role of culture in the merger and acquisition process: Evidence from the European chemical industry. Management Decision, 44(10), 1405-1421.

Marmenout, K. (2010). Employee Sense making in Mergers: How Deal Characteristics Shape Employee Attitudes. Journal of Applied Behavioral Science, 46(3), 329-359.

Panchal, S. \& Cartwright, S. (2001). Group Differences in Post-Merger Stress. Journal of Managerial Psychology, 16(6), 424-433.

Rajeshwari, T. R. (1992). Employee Stress: A Study with Reference to Bank Employees. Indian Journal of Industrial Relations, 27(4), 419-429.

Ranft, A. L. (2006). Knowledge preservation and transfer during post-acquisition integration. In Cary L. Cooper, Sydney Finkelstein (ed.) Advances in Mergers \& Acquisitions, (5), pp.51-67. Emerald Group Publishing Limited.

Sakas, D. \& Triantafyllopoulos, Y. (2009). Lessons from a case study for Greek banking M\&A negotiations. Management Decision, 47(8), 1300-1312.

Schweiger, D. \& Denisi, A. (1991). Communication with employees following a merger: a longitudinal field experiment. Academy of Management Journal, 34(1), 110-135.

Schweiger, D. L. \& Ivancevich, J. (1985). Human resources: The forgotten factor in mergers and acquisitions. Personnel Administrator, 2, 47-61.

Schweiger, D. M. \& Weber, Y. (1989). Strategies for managing human resources during mergers and acquisitions: An empirical investigation. Human Resource Planning, 12(2), 69-86.

Shook, L. \& Roth, G. (2011). Downsizings, mergers, and acquisitions: Perspectives of human resource development practitioners. Journal of European Industrial Training, 35(2), 135-153.

Weber, Y. (1996). Corporate culture fit and performance in mergers and acquisitions. Human Relations, $49(9), 1181-1202$. 
Weber, Y., Shenkar, O. \& Raveh, A. (1996). National and Corporate Cultural Fit in Mergers/Acquisitions: An Exploratory Study. Management Science, 42(8), 1215-1227.

Zollo, M. \& Singh, H. (2004). Deliberate learning in corporate acquisitions: post-acquisition strategies and integration capability in U.S. bank mergers. Strategic Management Journal, 25(13), 1233-1256.

\section{Web sites:}

http://www.rbi.org.in/scripts/BS_PressReleaseDisplay.aspx?prid=22977

http://www.stress.org/topic-definition-stress.htm 